\title{
The Common Leukemic Fusions in Pathogenesis and in Treatment Response in Acute Myeloid Leukemia
}

\author{
Temesgen Fufan, Shafqat Ahmed and Jenny L. Persson ${ }^{*}$
} Division of Experimental Cancer Research, Department of Laboratory Medicine, Clinical Research Center in Malmö,
Lund University, 205 02, Malmö, Sweden

\begin{abstract}
Chromosomal abnormalities are the most common alterations in acute myeloid leukemia (AML). Among those abnormalities, chromosomal translocations that produce the oncogenic fusion proteins have been frequently observed in different subtypes of AML. Although molecular mechanisms underlying the consequences of the oncogenic transformation resulted from the fusion proteins have been extensively studied, little is known about the molecular events cooperative with the oncogenic fusion proteins in the pathogenesis of leukemia and the cellular mechanisms with regard to the predictive roles of the fusions in treatment response. In this article, we will present an overview of the important aspects of AML-associated fusion proteins and their regulated transcriptional networks in pathogenesis and prognosis of AML. We will also discuss the recent findings pertaining to the functional link between the oncogenic fusions and response of leukemic cells to the treatment. Understanding the regulation of AML-associated fusions and their association with disease characteristics, patient outcome and treatment response will be of fundamental importance for predicting the effectiveness of the treatment and design the specific therapeutic strategies.
\end{abstract}

Keywords: Acute myeloid leukemia, chromosome translocations, leukemic fusion proteins, transcriptional factors, treatment response.

\section{INTRODUCTION}

Hematopoiesis is a complicated multistage process that involves the differentiation and maturation of different blood cell types. Thus, to terminally differentiate and mature, cells have to pass through hierarchy of successive developmental stages $[1,2]$. In each stage, the regulatory genes for hematopoiesis are either activated or silenced in a cell typespecific or lineage-specific manner to ensure a precise finetuning of the process [3-7]. The disruption of this regulatory process may result in different types of blood disorders. Acute myeloid leukemia (AML) is one of the major blood disorders that are associated with disruption of the regulatory processes.

AML is characterized by accumulation of cells at the early stages of the differentiation process [8-10]. This is mostly attributed to dysfunctional regulatory transcription factors, resulting in aberrant gene expression and function [7, 9]. Dysfunction of the regulatory transcription factors in turn results in blocking of the passage of cells through a given developmental stage depending on the subtype of the disease [7]. Thus, AML is a heterogenous disease, which comprises multiple subtypes $[11,12]$. The subtypes are classified according to the $\mathrm{FAB}$ classification system. The subtypes are denoted as M0-M7 [2, 4, 10, 13]. The grouping is made based on the degree of granulocytic maturation (M1, M2, M3) or monocytic differentiation (M4 \& M5) or presence of large number of erythroblasts (M6) or magakaryoblasts (M7)

*Address correspondence to this author at the Clinical Research Cancer, Division of Experimental Cancer Research, Lund University, Malmö University Hospital, 205 02, Malmö, Sweden; Tel: +46-40-391106; Fax: +46-40-391222; E-mail: jenny_l.persson@med.lu.se
$[10,13]$. The individual subtypes of this heterogenous disease can be identified using multiple methods such as cellular morphology, cytochemistry, immunophenotypes and molecular analysis [14]. For instance, in the most common forms of leukemia, acute promyelocytic leukemia (APL), and acute myeloid leukemia, the differentiation process is blocked at a promyelocyte stage [15], and early myeloid stage [16], respectively. The blocked cells regain a selfrenewal capacity and continue to proliferate and overpopulate the bone marrow. The prognosis of leukemia varies in patients depending on ages of the patients. Combination of age, cytogenetics, and white blood cell count (WBC) is a good prognostic factor. Young age tends to be associated with favorable prognosis, while old age is associated with poor prognosis [13, 17]. Cytochemical staining for example is helpful in differentiating AML from ALL as well as identifying subtypes of AML [14]. On the other hand, the specific karyotype is age-independent predictor of the treatment outcome. For example, the $t(8$; $21)$, inv(16) and $t(15 ; 17)$ are indicators of favorable prognosis while, deletion or loss of chromosome 5 or 7 or both is associated with poor prognosis [13]. Multiple parameters have been taken into consideration for accurate diagnosis and better choice of treatment regimens. Genomewide studies in search of complex genetic alterations and identification of possible novel markers have provided novel tools for the diagnosis and treatment of AML [16].

In AML, the underlying genetic or epigenetic events lead to disruption of this delicate regulatory mechanism affecting multiple cellular processes and regulatory pathways, especially the stage-specific regulations $[6,16]$. A large number of diverse translocations have been described. The most frequent are the $\mathrm{t}(8 ; 21), \mathrm{t}(15 ; 17)$, inv(16) which 
together with their variants, account for approximately $40 \%$ of all AMLs [7]. These translocations produce the AML1/ETO, PML/RAR $\alpha$, CBFCBF $\alpha$ \& CBF $\beta / \mathrm{SMMHC}$ fusion proteins, respectively [18] and the RAR $\alpha$ [15]. These transcription factors are among the most important regulatory proteins that contribute to the normal differentiation and maturation of hematopoietic cells.

Great efforts have been made in treating leukemia to improve the clinical remission and disease-free survival. However, it is important to eliminate the unnecessary side effects that are usually associated with chemotherapy treatment and to improve specificity of drugs. Further, it remains to be investigated in detail whether the leukemic fusions are associated with leukemic subtypes and treatment response.

\section{THE AML1}

The core binding factors are a small family of transcription factors $\mathrm{CBF}$ comprising a DNA binding $\mathrm{CBF} \alpha$ subunit and a non-DNA binding $\mathrm{CBF} \beta$ subunit. The gene encoding $\mathrm{CBF} \alpha$ subunit, AML1 (also known as Runx1, CBFA2, and PEBPA2A), together with the gene encoding $\mathrm{CBF} \beta$ subunit are essential for hematopoiesis and are frequently fused with other genes to produce fusion genes in human leukemias [4, 19-23]. The gene for AML1, is located in $21 \mathrm{q} 22$, while the gene for CBF $\beta$, is located on $16 \mathrm{q} 22$ [4, 24, 25-30]. AML1 is the part that contains a DNA-binding and a trans-activation domain, while the $\mathrm{CBF} \beta$ does not contain any known DNA-binding or a trans-activation domain $[4,21,26,31,32]$. However, it is believed that the CBF $\beta$ subunit strengthens the binding of the AML1 $[31,33]$. Furthermore, the CBF $\beta$ is believed to stabilize the AML1 by protecting it from ubiquitin-mediated degradation [21, 33]. Disruption in each subunit will result in total loss of function of the CBF. Since both subunits are equally important for the function of the CBF, knock-in of the AML1-fusion gene exerts similar phenotype as a AML1 knockout [4, 28]. This notion is supported by the fact that disruption of the CBF $\beta$ results in similar phenotype as the disruption of the AML1 [4, 30, 34, 35].

The CBF plays critical roles in lineage commitment of myeloid progenitors and terminal differentiation of hematopoietic cells $[31,36]$. Many myeloid-specific regulatory genes have cis-acting binding sites for AML1, and activation of these genes are believed to be critical for the normal granulocyte development [3]. When the function of the $\mathrm{CBF}$ is affected by leukemogenesis, the development of the granulocytes is also affected [37]. Although the CBF $\beta$ is ubiquitously expressed, its function is not well-studied [38]. However, knockout of either AML1 or CBF $\beta$ in mice results in embryonic lethality $[18,22,39-42]$. It is not clear whether AML1 or CBF $\beta$ contributes to fetal hematopoiesis through additional pathways. Identification of the upstream actors or downstream targets of the AML1 might be helpful in designing disease-specific therapeutic methodologies.

\section{THE AML1 FUSIONS IN LEUKEMIA}

The most commonly $\mathrm{t}(8 ; 21), \mathrm{t}(12 ; 21)$, and $\mathrm{t}(3 ; 21)$ for AML1 generate fusions that are frequently observed in M1 and M2 subtypes of myeloid leukemia [26, 30]. The chromosomal translocation $\mathrm{t}(8 ; 21)$ represents significant portion of the M2 subtype of AML [19, 43-45]. This translocation fuses AML1 (RUNX1) to ETO creating a novel hybrid AML1/ETO gene [24, 46-53]. The AML1-ETO interacts with other transcriptional factors act as repressors such as $\mathrm{N}-\mathrm{CoR}, \mathrm{mSin} 3 \mathrm{~A}$ and HDACs through its ETO part $[9,33,37]$. Thus, the fusion protein exhibits dominant negative effect over the wild type AML1 inhibiting transcription of the normally AML1-regulated genes that are essential for hematopoiesis [43, 51, 54-56]. Biological features of the fusion AML1-ETO is the disruption of hematopoiesis including the hypergranulation and strong myeloperoxidase-positivity of hematopoietic cells $[31,57$, 58].

\section{TREATMENT RESPONSE IN PATIENTS WITH AML1-ETO}

Choice of appropriate regimens for treatment of leukemias is mainly based on accurate diagnosis. The major treatment choice is the classical chemotherapy [10]. The M2 AML responds well to high dose cytarabine exhibiting high remission rate and long disease-free survival [57]. Particularly, the AML1/ETO is serving as a paradigm for the M2 subtype of AML due partly to its high percentage of incidence that constitutes about $40 \%$ the M2 subtype [43, 58]. Patients who harbor AML1/ETO fusion have favorable prognosis. Patients presenting AML1/ETO normally do not directly require bone marrow transplantation, and thus the transplantation related complications may be avoided in these patients [2]. However, high dose cytarabine is associated with multiple side effects such as cardiovascular and central nervous system damages.

\section{Leukemia Related to the $\operatorname{Inv}(16)$}

Inv(16) for CBF $\beta$ is a result of a pericentric inversion of chromosome 16 [4, 24-30, 59-61]. This inversion results in fusion of the CBF $\beta$ in frame to a myosin heavy chain gene (MYH11), which is located on the short arm (16p13) of the chromosome [4, 30, 59]. This chromosomal abnormality creates a novel hybrid gene (CBF $/$ MYH11), which is expressed to produce a $\mathrm{CBF} \beta / \mathrm{SMMHC}$ chimeric protein $[4$, $24,62,63]$. The chimeric protein is composed of the first 165 amino acids of $\mathrm{CBF} \beta$ and a half part of SMMHC including its coiled-coil domain [26, 32, 62, 64]. The chimeric protein is still able to heterodimerize with AML1 $[65,66]$. In fact, it has been reported that $\mathrm{CBF} \beta / \mathrm{SMMHC}$ binds to AML1 more avidly and with altered stochiometry [32]. This translocation is exclusively associated with the M4eo subtype of AML [24, 50, 59, 62, 67-70]. The M4eo is associated with abnormal eosinophils $[12,25,26,30,59,67$, 70]. The M4eo exhibits similar response to chemotherapy as that of the M2 subtype [40]. Similar to the AML1-ETO fusion, the $\mathrm{CBF} \beta / \mathrm{SMMHC}$ protein exerts dominant negative effect on the wild type AML1 [4, 27, 30, 32, 35, 64, 71, 72]. The CBF $\beta / \mathrm{SMMHC}$ can sequester the AML1 into nonfunctional complex thus acting as an inhibitor of the $\mathrm{CBF}$ $[73,74]$. Furthermore, the dominant inhibitory function of the $\mathrm{CBF} \beta / \mathrm{SMMHC}$ is partly attributed to sequesteration of the AML1 in the cytoplasm [26, 28, 36, 75]. Mice chimeras that express $\mathrm{CBF} \beta / \mathrm{SMMHC}$ exhibit a phenotype similar to AML1 or CBF $\beta$ null mice $[28,63,72,73]$, and these observations emphasize that the inv(16) most likely exploit 
similar biochemical mechanisms that are exploited by the other CBF leukemias to establish its effects.

\section{Leukemia Related to the $t(3 ; 21)$}

This chromosomal translocation is relatively rare and it is tightly associated with chemotherapy-related myelodysplastic syndrome (MDS) and chronic myelogenous leukemia (CML) [4, 21, 76]. This translocation fuses AML1 to EPA, MDS1 or EVI1, depending on the location of the breakpoint within chromosome 3 , because all the three genes are located within the same region of the long arm of the chromosome $[21,50,77]$. In any case, transcription of the fusion gene is driven by AML1 promoter [78]. The $t(3 ; 21)$ may be induced by the chemotherapeutic agents including topoisomerase II inhibitors in patients [21]. EAP is a highly expressed small nuclear proteins related to Epstein-Barr virus small RNA [21]. MDS1 encodes for small RNA of unknown function, while EVI1 gene encodes a zinc finger transcription factor that seems to be involved in transactivation of some genes $[21,78-80]$ such as $c$-Fos [21]. In summary, all the AML1fusion products disrupt the normal function of the AML1, resulting in similar overall disease characteristics of the AML [4, 27].

\section{TREATMENT RESPONSE IN PATIENTS WITH CBF FUSIONS}

The CBF leukemias are responsive to the standard chemotherapy regimens such as the combination of anthracyclines and cytarabine (Ara-C) [57]. The intention of induction therapy is to achieve a clinical remission [10]. Once clinical remission is achieved, it is followed by postremission therapy which can be categorized as consolidation therapy or maintenance therapy. The purpose of consolidation therapy is to eradicate residual leukemic cells [10], while maintenance therapy is to preventing relapse. However most of the chemotherapeutic agents are not specific to the leukemic cells. They also attack the normal cells that are actively dividing. Such cells include the skin cells, immune cells, hair follicles, and cells of gastrointestinal lining. Therefore, the reversible side effects include skin rush, hair loss, nausea, vomiting, diarrhea, and poor appetite are frequently associated with the treatment. The irreversible side effects may further include permanent organ damage and introduction of secondary malignancies. Thus, although chemotherapy is effective for treatment of leukemia, it is an urgent need for develop novel treatment agents that can minimize the side-effects.

\section{THE RETINOIC ACID RECEPTOR $\alpha(\operatorname{RAR} \alpha)$}

Within the steroid/thyroid nuclear receptors, the subfamily of the retinoic acid receptors is composed of RARs and RXRs, each consisting of different isotypes $(\alpha, \beta$, and $\gamma$ ) and each isotype is encoded by different genes [81, 82]. All of the RAR family members (RAR $\alpha, \beta$, and $\gamma$ ) are activated by retinoic acids (RAs) [82]. The RAR $\alpha$ is a ligand-activated nuclear transcription factor [68, 81, 83, 84]. Retinoid-induced RAR $\alpha$ regulate various cellular processes form embryonic development to maintenance of homeostasis and induction of cell death in adults [85, 82]. RAR $\alpha$ functions as a heterodimer and its heterodimeric partner is the $\operatorname{RXR} \alpha[83,86]$. In the absence of the ligands, the
$\mathrm{RAR} \alpha / \mathrm{RXR} \alpha$ heterodimers are believed to function as transcriptional inhibitors. The binding of the ligands coverts these transcriptional inhibitors into transcriptional activators, possibly by inducing conformational changes. The activated RARs in general bind to the response elements within the promoter regions of the RAR $\alpha$-regulated genes and induce gene expression, in general [83, 87]. Since the RARs are pleiotropic, treatment of multipotent cells such as FDCP mixA4 with erythropoietin results in inhibition of RAR $\alpha$ and commitment of the cells into erythroid lineage, while treatment with G-CSF results in upregulation of expression of $\operatorname{RAR} \alpha$ resulting in commitment of the cells into myeloid lineage $[84,88]$. Lines of evidence strengthen the notion that the AR/RAR $\alpha$ signaling is necessary for neutrophil maturation. Transgenic mice harboring a mutation within ligand-binding domain of RAR $\alpha$ exhibit increased immature neutrophil cell count suggesting the importance of RAR $\alpha$ in neutrophil maturation [83]. The RAR $\alpha$ pathway also plays very important roles driving the pluripotent hematopoietic cells along the granulocytic lineage [88-90].

\section{RAR A ASSOCIATED FUSIONS IN SUBTYPES OF ACUTE MYELOID LEUKEMIA}

The APL is a subtype of AML with a differentiation blockage at a promyelocytic stage of myeloid cell maturation $[81,91,92]$. Thus, the APL is characterized by expansion or proliferation of the myeloid lineage blocked at a promyelocyte stage of differentiation [10,92-94]. This group of disease is generally categorized as a FAB M3 subtype of the AML, while the $t(15 ; 17)$ is the most representative of the group. The unique cytogenetic abnormalities that are tightly associated with APL are the chromosomal translocations that target RAR $\alpha[81,95]$. The genetic abnormalities underlying the initiation or the progression or the manifestation of APL include the chromosomal translocations $\mathrm{t}(15 ; 17)(\mathrm{q} 22 ; \mathrm{q} 21)$, $\mathrm{t}(11 ; 17)(\mathrm{q} 23 ; \mathrm{q} 21), \mathrm{t}(11 ; 17)(\mathrm{q} 13 ; \mathrm{q} 21), \mathrm{t}(5 ; 17)(\mathrm{q} 35 ; \mathrm{q} 21)$ and der(17) [83]. These reciprocal chromosomal translocations fuse RAR $\alpha$ to different partners such as PML, PLZF, NuMA, NPM, and STAT5b respectively [15, 81, 96-98].

The leukemia that is cytogenetically characterized as having the $\mathrm{t}(15 ; 17)$ chromosomal translocation is categorized as the M3 subtype of AML, which is also known as APL $[89,98-102]$. The $\mathrm{t}(15 ; 17)(\mathrm{q} 22 ; \mathrm{q} 21)$ is the most common form of the chromosomal translocations that target RAR $\alpha$, and seems to be responsible for transformed phenotype of APL $[12,15,68,81,83,88,91]$. This chromosomal translocation represents over 95\% clinically relevant APL cases $[1,27,83]$. The PML/RAR $\alpha$ may disrupt the normal function of RAR $\alpha$ and PML [24, 98]. APL that harbors $\mathrm{PML} / \mathrm{RAR} \alpha$ fusion respond well to the current therapeutic regimens and exhibit favorable prognosis [101, 102].

The $\mathrm{t}(11 ; 17)(\mathrm{q} 23 ; \mathrm{q} 21)$ is also clinically relevant accounting for about $0.8 \%$ of APL cases [83]. This translocation fuses PLZF in frame to RAR $\alpha$ creating a disease-specific hybrid gene (PLZF/RAR $\alpha$ ) [83, 103]. PLZF is a zinc finger transcription factor which seems to be expressed during early stage of hematopoietic cell development [83, 104]. PLZF may play important roles in maintenance or survival of early progenitor cells. PZLF is also known to regulate some powerful regulatory genes such as $c-m y c$, cyclin A2. Therefore, PZLF may have direct or 
indirect tumor-suppressor activity that is disrupted by the chromosomal translocation. Unlike the PML/RAR $\alpha$ containing cells, the PLZF/RAR $\alpha$ containing cells do not respond to ATRA $[81,98]$.

The $\mathrm{t}(5 ; 21)(\mathrm{q} 35 ; \mathrm{q} 21)$ only represents less than $0.5 \%$ of the clinically relevant APL cases [83]. This translocation fuses NPM in frame with RAR $\alpha$ again creating a diseasespecific hybrid gene [83]. The NPM/RAR $\alpha$ fusion protein is believed to disrupt the normal function of RAR $\alpha$ [83]. NPM is a nuclear phosphoprotein that is ubiquitously expressed $[83,105]$. Its main function is believed to be transportation of ribosomal materials between the nucleolus and the cytoplasm [83]. NPM is also a target of other chromosomal translocations [83], implying involvement of the protein in important regulatory processes. This protein is also implicated in regulation of $\mathrm{p} 53$, because it was found directly binding and stabilizing p53 in the events such as cellular stresses that induce expression of p53 [83, 105]. The APL cells that harbor the $\mathrm{t}(5 ; 17)(\mathrm{q} 35 ; \mathrm{q} 21)$ have favorable prognosis because they respond well to ATRA treatment [81, 83].

The $\mathrm{t}(11 ; 17)(\mathrm{q} 13 ; \mathrm{q} 21)$ is a rare chromosomal translocation that fuses NuMA to RAR $\alpha$ [83]. This translocation also exhibit favorable prognosis because it is sensitivity to ATRA [83]. NuMA seems to have important roles in mitosis, specifically in formation of spindle asters, and in re-formation of daughter nuclei [83, 106], and microtubule assembly [107]. Like the other RAR $\alpha$ partners, RAR $\alpha-N u M A$ disrupts the normal function of RAR $\alpha$ and may lead to the leukemogenesis [81,83].

In der (17) chromosomal abnormality, an interstitial deletion spanning a $3 \mathrm{Mb}$ DNA region on the long arm of chromosome 17 results in the fusion of $S T A T 4 b$ with RAR $\alpha$ [83]. This event is very rare and its response to therapeutic regimens has not been determined. The $S T A T 5 b$ belongs to a family of transcription factors that are involved in multiple cellular processes and their aberrant expression is implicated in many cancer types including leukemia [83]. STAT5b is widely expressed including in hematopoietic progenitors [83]. Like the other RAR $\alpha$ partners, this protein heterodimerizes with its coiled-coil motif. Disruption of the normal function of RAR $\alpha$ as well as that of STAT5b could contribute to the leukemogenesis, although the function of $S T A T 5 b$ is not known.

\section{TREATMENT RESPONSE IN PATIENTS WITH RARA FUSIONS}

The most studied and better understood mechanism exploited by the fusion proteins is to recruit the transcriptional corepressors to the $\mathrm{RAR} \alpha$ regulated gene promoters, thus preventing $\mathrm{RAR} \alpha$ to activate its targeting genes that are important for hematopoiesis [33, 108]. It has been established that $\operatorname{RAR} \alpha$ and AML1 interacts with corepressors including N-CoR, mSin3A and HDACs [4, 21, 51, 109-112]. The classical treatment of APL is the intensive chemotherapy. Overall, APL exhibits favorable prognosis due to its sensitivity to treatment in general [113]. During the last 15 years, ATRA has become the mainstay of the treatment of APL [86, 96, 114]. Although a physiological concentration of ATRA is not effective, a pharmacological concentration of ATRA causes terminal differentiation of leukemic cells, and results in long term survival in APL patients [86, 88, 115, 116]. Furthermore, simultaneous administration of chemotherapy and ATRA has improved the remission rate and significant reduction of relapse risk $[10,97]$. This combination therapy is more effective than either chemotherapy or ATRA alone and improved an overall survival rate $[10,97]$. Although the mechanism of action of ATRA is not clear, it is believed that ATRA forces the APL cells into neutrophil-like differentiation [81, 84, 85, 88], which ultimately leads to apoptosis [81]. ATRA acts through the RAR $\alpha$ signaling pathway $[82,84]$. ATRA is also is believed to be involved in interferon signaling pathways because induction of interferon regulatory factor-1 (IRF-1) has been observed during ATRA treatment, and IRF-1 induces expression of interferons, which ultimately lead to apoptosis and cell death [84]. Most recently, use of an old medicine, $\mathrm{As}_{2} \mathrm{O}_{3}$, in APL has proven useful because it induces apoptosis in APL cells that are resistant to ATRA [81]. Furthermore, $\mathrm{As}_{2} \mathrm{O}_{3}$ has proven itself to be effective to treat the APL patients at disease recurrence [97].

Although positive results have been achieved in treating APL, significant problems remain to be solved. For instance, APL is linked to bleeding diathesis which occurs during early stage of the treatment. The bleeding seems to occur due to disseminated intravascular coagulation and excessive fibrinolysis [81]. Severe coagulation that can lead to hemorrhagic complications has become clinical feature of the disease [97]. The coagulopathy is usually triggered or more exacerbated by chemotherapy leading to high induction death rate at $10 \%$, meanwhile increased awareness has resulted in better supportive care that resulted in decreased induction death [97]. The side effects including fever, respiratory distress, pleural or pericardial effusion and interstitial lung infiltration usually occur during the first month of treatment and occasionally immediately after administration of the first dose of ATRA [81]. These side effects are so serious that if left untreated, they can lead to hypoxia, respiratory failure and ultimate death [81]. Other common and reversible side effects associated with ATRA treatment are headache, dry skin and mucosal membrane [81]. Hence, better treatment methods and regimens that eliminate the unnecessary side effects that affect the quality of life of the patients are urgently needed.

\section{THE COMMON CHARACTERISTICS OF THE CBF AND RAR $\alpha$, ASSOCIATED-FUSION PROTEINS AND NOVEL THERAPEUTIC APPROACHES}

Remarkably, despite the structural and functional divergences among the fusion partners of the CBF and the RAR $\alpha$, the fusion proteins exploit similar, if not identical biochemical mechanisms to exert their dominant inhibitory efforts. The recruitment of corepressors and HDACs accompanied by some epigenetic changes such as hypermethylation of the promoters result in effective inhibition of gene expression [97]. It has been established that the AML1/ETO chimeric protein interacts with corepressors including $\mathrm{N}-\mathrm{CoR}, \mathrm{mSin} 3 \mathrm{~A}$ and HDACs [4, 21, 51, 109-111]. The ETO part of the chimeric protein is responsible for the recruitment of the corepressors $[4,43,54$, 113]. The $\operatorname{RAR} \alpha /$ fusion proteins also recruit corepressors and HADC-complexes in order to repress the genes that are normally activated by $\operatorname{RAR} \alpha[83,110]$. In deed, it has been 
demonstrated that the RAR $\alpha$ fusion proteins recruits $\mathrm{N}-\mathrm{CoR}$ and HDAC3 [108]. The PML/RAR $\alpha$ fusion protein in particular recruits $\mathrm{N}-\mathrm{CoR} / \mathrm{Sin} 3 / \mathrm{HDAC} 1$ complex to RAR $\alpha$ target promoter regions and inhibits transcription [68]. These unifying themes of the diverse subtypes of leukemia may offer the opportunity for designing a single treatment agent that can specifically target the leukemic cells and improve therapeutic efficacy compared to the classical chemotherapy. The CBF leukemias and the RAR $\alpha$-targeting APL all exploit similar biochemical mechanisms including recruitment of HDACs to the promoter region of the genes that play crucial roles in hematopoiesis [33]. Usage of HDAC inhibitors is underway in research laboratories and shows some promising results [117]. For instance, treatment of leukemia cell lines with valproic acid (VPA) has shown encouraging results [117]. VPA is known to selectively inhibit some HDACs. Treatment of cell lines that harbor AML1/ETO with VPA resulted in inhibition of the recruitment of HDACs by AML1/ETO and induced histone hyperacetylation, which resulted in re-expression of the AML1/ETO repressed genes [117]. HDAC inhibitors are not as dangerous as chemotherapy because they exert their therapeutic effects at the epigenetic level, and therefore can offer milder yet effective treatment choice.

Molecular and gene targeting therapeutic approaches have been tested. Specific protein redirection as a transcriptional therapy approach for $t(8 ; 21)$ has been attempted [118]. In another study, overexpression of the domains of the fusion proteins that recruit corepressors has been attempted in cell lines that harbor the leukemic fusion genes [119]. In the protein redirection approach, it was intended to remove the fusion proteins such as the AML1/ETO form the AML1-regulated gene promoters. Epigenetic therapy combined with some molecular targeting methodologies might offer safer and more effective therapeutic choice in the future.

\section{FUTURE PERSPECTIVE}

Genome-wide studies have allowed identification and further classification of risk groups and subtypes of AML. Gene-expression profiling allows a comprehensive classification of AML that includes previously identified genetically defined subgroups and a novel cluster with an adverse prognosis [120]. A unique cluster with a distinctive gene-expression signature included cases of AML with a poor treatment outcome has been identified [121]. The biological and prognostic heterogeneity of CBF-AML subtypes, including gene mutation and gene expression profiles as well as molecular response to therapy needed to be further studied. The future studies to address the heterogeneity and sub-risk group of CBF-AML will help to design a unique predefined strategy to treat these patients. Prognostic significance of microRNA expression signatures associated with, for example, CEBPA mutations in cytogenetically normal acute myeloid leukemia with highrisk molecular features have been investigated [122]. More comprehensive gene-expression signature-based and microRNA expression-based classifiers are needed for predicting outcome for individual patients with greater accuracy in the future diagnostics. This information is likely to have a major impact on the clinical management of in selection of appropriate treatment, since many of the identified genetic alterations already constitute or will potentially become targets for specific therapeutic intervention. The molecular effects induced by chemotherapeutic agents such as panobinostat and doxorubicin have been investigated by analyzing gene expression, cell cycle, apoptosis and signaling pathways. Analyses of gene expression profiles identified many genes whose expression was exclusively affected by the combination of panobinostat and doxorubicin [123]. Molecular cytology and pathology will have a great future impact on the precise classification of subtypes of leukemia and define the risk groups for diagnostics and prognostics and treatment respond. These novel approaches will help clinicians to design unique strategies to treat individual patients and to minimize the side-effects.

\section{ACKNOWLEDGEMENTS}

JLP was funded by the Swedish Cancer Society, the Swedish Children Foundation, The Swedish National Research Council, Malmö Hospital Cancer Foundation, Malmö Hospital Foundation, Crafoord Foundation and Gunnar Nilsson Cancer Foundation.

\section{REFERENCES}

[1] Lutz PG, Moog-Lutz C, Cayre YE. Signaling revisited in acute promyelocytic leukemia. Leukemia 2002; 16: 1933-9.

[2] Speck NA, Gilliland DG. Core-binding factors in haematopoiesis and leukaemia. Nat Rev Cancer 2002; 2: 502-13.

[3] Skalnik DG. Transcriptional mechanisms regulating myeloidspecific genes. Gene 2002; 284: 1-21.

[4] Kurokawa M, Hirai H. Role of AML1/Runx1 in the pathogenesis of hematological malignancies. Cancer Sci 2003; 94: 841-6.

[5] Ichikawa M, Asai $\mathrm{T}$, Saito $\mathrm{T}$, et al. AML-1 is required for megakaryocytic maturation and lymphocytic differentiation, but not for maintenance of hematopoietic stem cells in adult hematopoiesis. Nat Med 2004; 10: 299-304.

[6] Alcalay M, Orleth A, Sebastiani C, et al. Common themes in the pathogenesis of acute myeloid leukemia. Oncogene 2001;20: $5680-94$

[7] Look AT. Oncogenic transcription factors in the human acute leukemias. Science 1997; 278: 1059-64.

[8] Wildonger J, Mann RS. The t $(8 ; 21)$ translocation converts AML1 into a constitutive transcriptional repressor. Development 2005 132: 2263-72.

[9] Barseguian K, Lutterbach B, Hiebert SW, et al. Multiple subnuclear targeting signals of the leukemia-related AML1/ETO and ETO repressor proteins. Proc Natl Acad Sci USA 2002; 99: 15434-9.

[10] Bruserud O, Gjertsen BT, Huang T. Induction of differentiation and apoptosis- a possible strategy in the treatment of adult acute myelogenous leukemia. Oncologist 2000; 5: 454-62.

[11] Bacher U, Kern W, Schnittger S, et al. Correlations of morphology according to FAB and WHO classification to cytogenetics in de novo acute myeloid leukemia: a study on 2,235 patients. Ann Hematol 2005; 84: 785-91.

[12] Burmeister T, Thiel E. Molecular genetics in acute and chronic leukemias. J Cancer Res Clin Oncol 2001; 127: 80-90.

[13] Cripe LD. Adult acute leukemia. Curr Probl Cancer 1997; 21: 1-64.

[14] McKenna RW. Multifaceted approach to the diagnosis and classification of acute leukemias. Clin Chem 2000; 46: 1252-9.

[15] Kalantry S, Delva L, Gaboli M, et al. Gene rearrangements in the molecular pathogenesis of acute promyelocytic leukemia. J Cell Physiol 1997; 173: 288-96.

[16] Niebuhr B, Fischer M, Täger M, et al. Gatekeeper function of the RUNX1 transcription factor in acute leukemia. Blood Cells Mol Dis 2008; 40: 211-8.

[17] Stone RM, O'Donnell MR, Sekeres MA. Acute myeloid leukemia. Hematology (Am Soc Hematol Educ Prog) 2004; 98-117.

[18] Okuda T, van Deursen J, Hiebert SW, et al. AML1, the target of multiple chromosomal translocations in human leukemia, is 
essential for normal fetal liver hematopoiesis. Cell 1996; 84: 321 30 .

[19] Melnick A, Carlile GW, McConnell MJ, et al. AML-1/ETO fusion protein is a dominant negative inhibitor of transcriptional repression by the promyelocytic leukemia zinc finger protein. Blood 2000; 96: 3939-47.

[20] Licht JD. AML1 and the AML1-ETO fusion protein in the pathogenesis of $\mathrm{t}(8 ; 21)$ AML. Oncogene 2001; 20: 5660-79.

[21] Perry C, Eldor A, Soreq H. Runx1/AML1 in leukemia: disrupted association with diverse protein partners. Leuk Res 2002; 26: 221 8.

[22] Li X, Vradii D, Gutierrez S, et al. Subnuclear targeting of Runx1 is required for synergistic activation of the myeloid specific M-CSF receptor promoter by PU.1. J Cell Biochem 2005; 96: 795-809.

[23] Petrovick MS, Hiebert SW, Friedman AD, et al. Multiple functional domains of AML1: PU.1 and $\mathrm{C} / \mathrm{EBP} \alpha$ synergize with different regions of AML1. Mol Cell Biol 1998; 18: 3915-25.

[24] Ma SK, Wan TS, Chan LC. Cytogenetics and molecular genetics of childhood leukemia. Hematol Oncol 1999; 17: 91-105.

[25] Reilly JT. Pathogenesis of acute myeloid leukaemia and inv(16)(p13;q22): a paradigm for understanding leukaemogenesis? Br J Haematol 2005; 128: 18-34.

[26] Kundu M, Liu PP. Function of the inv(16) fusion gene CBFßMYH11. Curr Opin Hematol 2001; 8: 201-5.

[27] Licht JD, Sternberg DW. The molecular pathology of acute myeloid leukemia. Hematology (Am Soc Hematol Educ Prog) 2005; 137-42.

[28] Krug U, Ganser A, Koeffler HP. Tumor suppressor genes in normal and malignant hematopoiesis. Oncogene 2002; 21: 3475-95.

[29] Zhang L, Lukasik SM, Speck NA, et al. Structural and functional characterization of Runx1, CBF $\beta$, and CBF $\beta$-SMMHC. Blood Cells Mol Dis 2003; 30: 147-56.

[30] Adya N, Stacy T, Speck NA, et al. The leukemic protein core binding factor $\beta$ (CBF $\beta$ )-smooth-muscle myosin heavy chain sequesters $\mathrm{CBF} \alpha 2$ into cytoskeletal filaments and aggregates. Mol Cell Biol 1998; 18: 7432-43.

[31] Downing JR. The AML1-ETO chimaeric transcription factor in acute myeloid leukaemia: biology and clinical significance. $\mathrm{Br} \mathrm{J}$ Haematol 1999; 106: 296-308.

[32] Lukasik SM, Zhang L, Corpora T, et al. Altered affinity of CBF $\beta$ SMMHC for Runx1 explains its role in leukemogenesis. Nat Struct Biol 2002; 9: 674-9.

[33] Asou N. The role of a Runt domain transcription factor AML1/RUNX1 in leukemogenesis and its clinical implications. Crit Rev Oncol Hematol 2003; 45: 129-50.

[34] Kundu M, Chen A, Anderson S, et al. Role of CBF $\beta$ in hematopoiesis and perturbations resulting from expression of the leukemogenic fusion gene CBFß -MYH11. Blood 2002; 100: 2449-56.

[35] Castilla LH, Wijmenga C, Wang Q, et al. Failure of embryonic hematopoiesis and lethal hemorrhages in mouse embryos heterozygous for a knocked-in leukemia gene CBF $\beta-M Y H 11$. Cell 1996; 87: 687-96.

[36] Hart SM, Foroni L. Core binding factor genes and human leukemia. Haematologica 2002; 87: 1307-23.

[37] Scandura JM, Boccuni P, Cammenga J, et al. Transcription factor fusions in acute leukemia: variations on a theme. Oncogene 2002; 21:3422-44.

[38] Wang Q, Stacy T, Miller JD, et al. The CBF $\beta$ subunit is essential for CBF $\alpha 2$ (AML1) function in vivo. Cell 1996; 87: 697-708.

[39] Gilliland DG, Jordan CT, Felix CA. The molecular basis of leukemia. Hematology (Am Soc Hematol Educ Prog) 2004; 80-97.

[40] Yokomizo T, Ogawa M, Osato M, et al. Requirement of Runx 1/AML1/PEBP2 $\alpha$ B for the generation of haematopoietic cells from endothelial cells. Genes Cells 2001; 6: 13-23.

[41] Ito Y. Oncogenic potential of the RUNX gene family: 'overview'. Oncogene 2004; 23: 4198-208.

[42] Levanon D, Groner Y. Structure and regulated expression of mammalian RUNX genes. Oncogene 2004; 23: 4211-9.

[43] Mulloy JC, Cammenga J, MacKenzie KL, et al. The AML1-ETO fusion protein promotes the expansion of human hematopoietic stem cells. Blood 2002; 99: 15-23.

[44] Tonks A, Pearn L, Tonks AJ, et al. The AML1-ETO fusion gene promotes extensive self-renewal of human primary erythroid cells. Blood 2003; 101: 624-32.
[45] Miyoshi H, Shimizu K, Kozu T, et al. Ohki M. t(8;21) breakpoints on chromosome 21 in acute myeloid leukemia are clustered within a limited region of a single gene. AML1. Proc Natl Acad Sci USA 1991; 88: 10431-4.

[46] Yuan Y, Zhou L, Miyamoto T, et al. AML1-ETO expression is directly involved in the development of acute myeloid leukemia in the presence of additional mutations. Proc Natl Acad Sci USA 2001; 98: 10398-403.

[47] Linggi B, Müller-Tidow C, van de Locht L, et al. The $\mathrm{t}(8 ; 21)$ fusion protein, AML1 ETO, specifically represses the transcription of the p14(ARF) tumor suppressor in acute myeloid leukemia. Nat Med 2002; 8: 743-50.

[48] Meyers S, Lenny N, Hiebert SW. The $t(8 ; 21)$ fusion protein interferes with AML-1B-dependent transcriptional activation. Mol Cell Biol 1995; 15: 1974-82.

[49] Meyers S, Downing JR, Hiebert SW. Identification of AML-1 and the $(8 ; 21)$ translocation protein (AML-1/ETO) as sequence-specific DNA-binding proteins: the runt homology domain is required for DNA binding and protein-protein interactions. Mol Cell Biol 1993; 13: $6336-45$.

[50] Lo Coco F, Pisegna S, Diverio D. The AML1 gene: a transcription factor involved in the pathogenesis of myeloid and lymphoid leukemias. Haematologica 1997; 82: 364-70.

[51] Lutterbach B, Westendorf JJ, Linggi B, et al. ETO, a target of $\mathrm{t}(8 ; 21)$ in acute leukemia, interacts with the $\mathrm{N}-\mathrm{CoR}$ and $\mathrm{mSin} 3$ corepressors. Mol Cell Biol 1998; 18: 7176-84.

[52] Yergeau DA, Hetherington CJ, Wang Q, et al. Embryonic lethality and impairment of haematopoiesis in mice heterozygous for an AML1-ETO fusion gene. Nat Genet 1997; 15: 303-6.

[53] Vangala RK, Heiss-Neumann MS, Rangatia JS, et al. The myeloid master regulator transcription factor PU.1 is inactivated by AML1ETO in t $8 ; 21)$ myeloid leukemia. Blood 2003; 101: 270-7.

[54] Hiebert SW, Lutterbach B, Amann J. Role of co-repressors in transcriptional repression mediated by the $\mathrm{t}(8 ; 21)$, $\mathrm{t}(16 ; 21)$, $\mathrm{t}(12 ; 21)$, and inv(16) fusion proteins. Curr Opin Hematol 2001; 8: 197-200.

[55] Peterson LF, Lo MC, Okumura AJ, et al. Inability of RUNX1/AML1 to breach AML1-ETO block of embryonic stem cell definitive hematopoiesis. Blood Cells Mol Dis 2007; 39: 321 8 .

[56] Follows GA, Tagoh H, Lefevre P, et al. Epigenetic consequences of AML1-ETO action at the human c-FMS locus. EMBO J 2003; 22: 2798-809.

[57] Mandelli F, Petti MC, Lo Coco F. Therapy of acute myeloid leukemia: towards a patient-oriented, risk-adapted approach. Haematologica 1998; 83: 1015-23.

[58] Nishida S, Hosen N, Shirakata T, et al. AML1-ETO rapidly induces acute myeloblastic leukemia in cooperation with the Wilms tumor gene, WT1. Blood 2006; 107: 3303-12.

[59] Poirel H, Radford-Weiss I, Rack K, et al. Detection of the chromosome 16 CBF $\beta$-MYH11 fusion transcript in myelomonocytic leukemias. Blood 1995; 85: 1313-22.

[60] Marlton P, Claxton DF, Liu P, et al. Molecular characterization of $16 \mathrm{p}$ deletions associated with inversion 16 defines the critical fusion for leukemogenesis. Blood 1995; 85: 772-9.

[61] Liu P, Tarlé SA, Hajra A, et al. Fusion between transcription factor $\mathrm{CBF} \beta / \mathrm{PEBP} 2 \beta$ and a myosin heavy chain in acute myeloid leukemia. Science 1993; 261: 1041-4.

[62] Huang G, Shigesada K, Wee HJ, et al. Molecular basis for a dominant inactivation of RUNX1/AML1 by the leukemogenic inversion 16 chimera. Blood 2004; 103: 3200-7.

[63] Tanaka Y, Fujii M, Hayashi K, et al. The chimeric protein, PEBP2 $\beta / \mathrm{CBF} \beta$-SMMHC, disorganizes cytoplasmic stress fibers and inhibits transcriptional activation. Oncogene 1998; 17: 699-708.

[64] Durst KL, Lutterbach B, Kummalue T, et al. The inv(16) fusion protein associates with corepressors via a smooth muscle myosin heavy-chain domain. Mol Cell Biol 2003; 23: 607-19.

[65] Shurtleff SA, Meyers S, Hiebert SW, et al. Heterogeneity in CBF $\beta /$ MYH11 fusion messages encoded by the inv(16)(p13q22) and the $\mathrm{t}(16 ; 16)(\mathrm{p} 13 ; \mathrm{q} 22)$ in acute myelogenous leukemia. Blood 1995; 85: 3695-703.

[66] Cao W, Adya N, Britos-Bray M, et al. The core binding factor (CBF) $\alpha$ interaction domain and the smooth muscle myosin heavy chain (SMMHC) segment of CBF $\beta$-SMMHC are both required to slow cell proliferation. J Biol Chem 1998; 273: 31534-40. 
[67] Shigesada K, van de Sluis B, Liu PP. Mechanism of leukemogenesis by the inv(16) chimeric gene CBF $\beta /$ PEBP2 $\beta$ MHY11. Oncogene 2004; 23: 4297-307.

[68] Berman JN, Look AT. Targeting transcription factors in acute leukemia in children. Curr Drug Targets 2007; 8: 727-37.

[69] Liu PP, Hajra A, Wijmenga C, et al. Molecular pathogenesis of the chromosome 16 inversion in the M4Eo subtype of acute myeloid leukemia. Blood 1995; 85: 2289-302.

[70] Schnittger S, Bacher U, Haferlach C, et al. Rare CBFB-MYH11 fusion transcripts in AML with inv(16)/t(16;16) are associated with therapy-related AML M4eo, atypical cytomorphology, atypical immunophenotype, atypical additional chromosomal rearrangements and low white blood cell count: a study on 162 patients. Leukemia 2007; 21: 725-31.

[71] Lutterbach B, Hou Y, Durst KL, et al. The inv(16) encodes an acute myeloid leukemia 1 transcriptional corepressor. Proc Natl Acad Sci USA 1999; 96: 12822-7.

[72] Castilla LH, Garrett L, Adya N, et al. The fusion gene CBFßMYH11 blocks myeloid differentiation and predisposes mice to acute myelomonocytic leukaemia. Nat Genet 1999; 23: 144-6.

[73] Britos-Bray M, Ramirez M, Cao W, et al. CBF $\beta-S M M H C$, expressed in M4eo acute myeloid leukemia, reduces p53 induction and slows apoptosis in hematopoietic cells exposed to DNAdamaging agents. Blood 1998; 92: 4344-52.

[74] Kummalue T, Lou J, Friedman AD. Multimerization via its myosin domain facilitates nuclear localization and inhibition of core binding factor (CBF) activities by the $\mathrm{CBF} \beta$-smooth muscle myosin heavy chain myeloid leukemia oncoprotein. Mol Cell Biol 2002; 22: 8278-91.

[75] Kanno Y, Kanno T, Sakakura C, et al. Cytoplasmic sequestration of the polyomavirus enhancer binding protein 2 (PEBP2)/core binding factor $\alpha(\mathrm{CBF} \alpha)$ subunit by the leukemia-related PEBP2/CBF $\beta$-SMMHC fusion protein inhibits PEBP2/CBFmediated transactivation. Mol Cell Biol 1998; 18: 4252-61.

[76] Zent CS, Mathieu C, Claxton DF, et al. The chimeric genes AML1/MDS1 and AML1/EAP inhibit AML1B activation at the CSF1R promoter, but only AML1/MDS1 has tumor-promoter properties. Proc Natl Acad Sci USA 1996; 93: 1044-8.

[77] Yin CC, Cortes J, Barkoh B, et al. $\mathrm{t}(3 ; 21)(\mathrm{q} 26 ; \mathrm{q} 22)$ in myeloid leukemia: an aggressive syndrome of blast transformation associated with hydroxyurea or antimetabolite therapy. Cancer 2006; 106: 1730-8.

[78] Kurokawa M, Mitani K, Imai Y, et al. The $\mathrm{t}(3 ; 21)$ fusion product, AML1/Evi-1, interacts with Smad3 and blocks transforming growth factor- $\beta$-mediated growth inhibition of myeloid cells. Blood 1998; 92: 4003-12.

[79] Tanaka T, Mitani K, Kurokawa M, et al. Dual functions of the AML1/Evi-1 chimeric protein in the mechanism of leukemogenesis in $\mathrm{t}(3 ; 21)$ leukemias. Mol Cell Biol 1995; 15: 2383-92.

[80] Kurokawa M, Mitani K, Irie K, et al. The oncoprotein Evi-1 represses TGF- $\beta$ signalling by inhibiting Smad3. Nature 1998; 394 : 92-6.

[81] Douer D. Transcription therapy for acute promyelocytic leukaemia. Expert Opin Investig Drugs 2000; 9: 329-46.

[82] Chambon PA. Decade of molecular biology of retinoic acid receptors. FASEB J 1996; 10: 940-54.

[83] Mistry AR, Pedersen EW, Solomon E, et al. The molecular pathogenesis of acute promyelocytic leukaemia: implications for the clinical management of the disease. Blood Rev 2003; 17: 71-97.

[84] Melnick A, Licht JD. Deconstructing a disease: RAR $\alpha$, its fusion partners, and their roles in the pathogenesis of acute promyelocytic leukemia. Blood 1999; 93: 3167-215.

[85] Fontana JA, Rishi AK. Classical and novel retinoids: their targets in cancer therapy. Leukemia 2002; 16: 463-72.

[86] Drumea K, Yang ZF, Rosmarin A. Retinoic acid signaling in myelopoiesis. Curr Opin Hematol 2008; 15: 37-41.

[87] Lefebvre B, Brand C, Lefebvre P, et al. Chromosomal integration of retinoic acid response elements prevents cooperative transcriptional activation by retinoic acid receptor and retinoid $\mathrm{X}$ receptor. Mol Cell Biol 2002; 22: 1446-59.

[88] Collins SJ. The role of retinoids and retinoic acid receptors in normal hematopoiesis. Leukemia 2002; 16: 1896-905.

[89] Gratas C, Menot ML, Dresch C, et al. Retinoid acid supports granulocytic but not erythroid differentiation of myeloid progenitors in normal bone marrow cells. Leukemia 1993; 7: 115662.
[90] Tocci A, Parolini I, Gabbianelli M, et al. Dual action of retinoic acid on human embryonic/fetal hematopoiesis: blockade of primitive progenitor proliferation and shift from multipotent/erythroid/monocytic to granulocytic differentiation program. Blood 1996; 88: 2878-88

[91] Duprez E, Wagner K, Koch H, et al. C/EBP $\beta$ : a major PMLRAR $\alpha$-responsive gene in retinoic acid-induced differentiation of APL cells. EMBO J 2003; 22: 5806-16.

[92] Merghoub T, Gurrieri C, Piazza F, et al. Modeling acute promyelocytic leukemia in the mouse: new insights in the pathogenesis of human leukemias. Blood Cells Mol Dis 2001; 27: 231-48.

[93] He LZ, Merghoub T, Pandolfi PP. In vivo analysis of the molecular pathogenesis of acute promyelocytic leukemia in the mouse and its therapeutic implications. Oncogene 1999; 18: 5278-92.

[94] Meani N, Minardi S, Licciulli S, et al. Molecular signature of retinoic acid treatment in acute promyelocytic leukemia. Oncogene 2005; 24: 3358-68.

[95] Hummel JL, Zhang T, Wells RA, et al. The retinoic acid receptor $\alpha$ $($ RAR $\alpha$ ) chimeric proteins PML-, PLZF-, NPM-, and NuMA-RAR $\alpha$ have distinct intracellular localization patterns. Cell Growth Differ 2002; 13: 173-83.

[96] Rego EM, Ruggero D, Tribioli C, et al. Leukemia with distinct phenotypes in transgenic mice expressing $\operatorname{PML} / \operatorname{RAR} \alpha$, PLZF/RAR $\alpha$ or NPM/RAR $\alpha$. Oncogene 2006; 25: 1974-9.

[97] Grimwade D, Lo Coco F. Acute promyelocytic leukemia: a model for the role of molecular diagnosis and residual disease monitoring in directing treatment approach in acute myeloid leukemia. Leukemia 2002; 16: 1959-73.

[98] Pandolfi PP. Oncogenes and tumor suppressors in the molecular pathogenesis of acute promyelocytic leukemia. Hum Mol Genet 2001; 10: 769-75.

[99] de Thé H, Chomienne C, Lanotte $M$, et al. The $\mathrm{t}(15 ; 17)$ translocation of acute promyelocytic leukaemia fuses the retinoic acid receptor $\alpha$ gene to a novel transcribed locus. Nature 1990; 347: 558-61.

[100] He LZ, Tribioli C, Rivi R, et al. Acute leukemia with promyelocytic features in PML/RAR $\alpha$ transgenic mice. Proc Natl Acad Sci USA 1997; 94: 5302-7.

[101] Koken MH, Reid A, Quignon F, et al. Leukemia-associated retinoic acid receptor $\alpha$ fusion partners, PML and PLZF, heterodimerize and colocalize to nuclear bodies. Proc Natl Acad Sci USA 1997; 94: 10255-60.

[102] Rego EM, He LZ, Warrell RP, Jr, et al. Retinoic acid (RA) and As2O3 treatment in transgenic models of acute promyelocytic leukemia (APL) unravel the distinct nature of the leukemogenic process induced by the PML-RAR $\alpha$ and PLZF-RAR $\alpha$ oncoproteins. Proc Natl Acad Sci USA 2000; 97: 10173-8.

[103] Chen SJ, Zelent A, Tong JH, et al. Rearrangements of the retinoic acid receptor $\alpha$ and promyelocytic leukemia zinc finger genes resulting from $\mathrm{t}(11 ; 17)(\mathrm{q} 23 ; \mathrm{q} 21)$ in a patient with acute promyelocytic leukemia. J Clin Invest 1993; 91: 2260-7.

[104] Chen Z, Brand NJ, Chen A, et al. Fusion between a novel Kruppellike zinc finger gene and the retinoic acid receptor- $\alpha$ locus due to a variant $\mathrm{t}(11 ; 17)$ translocation associated with acute promyelocytic leukaemia. EMBO J 1993; 12: 1161-7.

[105] Colombo E, Marine JC, Danovi D, et al. Nucleophosmin regulates the stability and transcriptional activity of p53. Nat Cell Biol 2002; 4: 529-33.

[106] Hsu HL, Yeh NH. Dynamic changes of NuMA during the cell cycle and possible appearance of a truncated form of NuMA during apoptosis. J Cell Sci 1996; 109: 277-88.

[107] Dionne MA, Howard L, Compton DA. NuMA is a component of an insoluble matrix at mitotic spindle poles. Cell Motil Cytoskeleton 1999; 42: 189-203.

[108] Atsumi A, Tomita A, Kiyoi H, et al. Histone deacetylase 3 (HDAC3) is recruited to target promoters by PML-RAR $\alpha$ as a component of the $\mathrm{N}-\mathrm{CoR}$ co-repressor complex to repress transcription in vivo. Biochem Biophys Res Commun 2006; 345 : 1471-80.

[109] Lausen J, Cho S, Liu S, et al. The nuclear receptor co-repressor (NCoR) utilizes repression domains I and III for interaction and corepression with ETO. J Biol Chem 2004; 279: 49281-8.

[110] Minucci S, Maccarana M, Cioce M, et al. Oligomerization of RAR and AML1 transcription factors as a novel mechanism of oncogenic activation. Mol Cell 2000; 5(5): 811-20. 
[111] Hildebrand D, Tiefenbach J, Heinzel T, et al. Multiple regions of ETO cooperate in transcriptional repression. J Biol Chem 2001; 276: 9889-95.

[112] Amann JM, Nip J, Strom DK, et al. ETO, a target of $\mathrm{t}(8 ; 21)$ in acute leukemia, makes distinct contacts with multiple histone deacetylases and binds $\mathrm{mSin} 3 \mathrm{~A}$ through its oligomerization domain. Mol Cell Biol 2001; 21: 6470-83.

[113] He LZ, Tolentino T, Grayson P, et al. Histone deacetylase inhibitors induce remission in transgenic models of therapyresistant acute promyelocytic leukemia. J Clin Invest 2001; 108: 1321-30.

[114] Guidez F, Ivins S, Zhu J, et al. Reduced retinoic acid-sensitivities of nuclear receptor corepressor binding to PML- and PLZF-RAR $\alpha$ underlie molecular pathogenesis and treatment of acute promyelocytic leukemia. Blood 1998; 91: 2634-42.

[115] Glasow A, Prodromou N, Xu K, et al. Retinoids and myelomonocytic growth factors cooperatively activate RAR $\alpha$ and induce human myeloid leukemia cell differentiation via MAP kinase pathways. Blood 2005; 105: 341-9.

[116] Pitha-Rowe I, Petty WJ, Kitareewan S, et al. Retinoid target genes in acute promyelocytic leukemia. Leukemia 2003; 17: 1723-30.

[117] Liu S, Klisovic RB, Vukosavljevic T, et al. Targeting AML1/ETOhistone deacetylase repressor complex: a novel mechanism for valproic acid-mediated gene expression and cellular differentiation in AML1/ETO-positive acute myeloid leukemia cells. J Pharmacol Exp Ther 2007; 321: 953-60.

[118] Steffen B, Serve H, Berdel WE, et al. Specific protein redirection as a transcriptional therapy approach for $\mathrm{t}(8 ; 21)$ leukemia. Proc Natl Acad Sci USA 2003; 100: 8448-53.

[119] Racanicchi S, Maccherani C, Liberatore C, et al. Targeting fusion protein/corepressor contact restores differentiation response in leukemia cells. EMBO J 2005; 24: 1232-42.

[120] Valk PJ, Verhaak RG, Beijen MA, et al. Prognostically useful gene-expression profiles in acute myeloid leukemia.. N Engl J Med 2004; 350:1617-28.

[121] Dombret H, Preudhomme C, Boissel N. Core binding factor acute myeloid leukemia (CBF-AML): is high-dose Ara-C (HDAC) consolidation as effective as you think? Curr Opin Hematol 2009; 16:92-7.

[122] Marcucci G, Maharry K, Radmacher MD, et al. Prognostic significance of, and gene and microRNA expression signatures associated with, CEBPA mutations in cytogenetically normal acute myeloid leukemia with high-risk molecular features: a Cancer and Leukemia Group B Study. J Clin Oncol 2008; 26: 5078-87.

[123] Maiso P, Colado E, Ocio EM, The synergy of panobinostat plus doxorubicin in acute myeloid leukemia suggests a role for HDAC inhibitors in the control of DNA repair. Leukemia 2009; 8. [Epub ahead of print].

(C) Fufan et al.; Licensee Bentham Open.

This is an open access article licensed under the terms of the Creative Commons Attribution Non-Commercial License (http: //creativecommons.org/licenses/by$\mathrm{nc} / 3.0 /$ ) which permits unrestricted, non-commercial use, distribution and reproduction in any medium, provided the work is properly cited. 